\title{
Adopting USER-CENTRED DEVELOPMENT For ARABIC E-COMMERCE WEBSITES
}

\author{
Ali Alghamdi ${ }^{1}$, Hamza Aldabbas ${ }^{1}$, Mohammad Alshehri ${ }^{1}$ and Muneer Nusir ${ }^{2}$ \\ ${ }^{1}$ Faculty of Technology, De Montfort University,Leicester, United Kingdom \\ $\{a l i$, hamza, mohammad\} @dmu.ac.uk \\ ${ }^{2}$ Department of Computer Science, University of Leicester, Leicester, UK \\ msanlele.ac.uk
}

\begin{abstract}
Over the past few years the Internet has become an essential business platform by aiding trading, distribution and sales between organisations, consumers, and even between consumers. This has brought ecommerce to an entirely new level which raised some issues in websites usability and the human-computer interaction. Therefore, the objectives of this paper are to identify and analyse the extent to which the site is fulfilling all the user's requirements and needs. The related work covers the history of human-computer interaction and the benefits of using user-centered approach, which is the methodology been used in this paper. Moreover, a brief comparison between the most important development methods, such as Waterfall and user-centred methods are discussed in terms of addressing the issues of time saving and addressing fulfilment of users' needs. In order to address most of the issues that is related to the attributes in the usability stage of the evaluation, the data required to manage this study was collected using three research methods; the questionnaire, direct user observation and interviews. An evaluation of the current websites, based on statements of usability goals and criteria were chosen from the Arabic guidelines in the literature, were undertaken in connection with implementing and testing the proposed websites design. Many famous Arabic websites such as JARIR bookstore and Ahmad Abdul wahed website were chosen as a case study in this paper to investigate the usability and interactivity of the websites design. The analysis section includes needs, users and tasks and data analysis, whereas the design phase includes the user interface and database design. At the end of this paper, some recommendations are presented regarding these website that can be considered in developing these website in the future.
\end{abstract}

\section{KEYWORDS}

E-commerce, Interaction design, Usability, User-centered development

\section{INTRODUCTION}

The amount of trade conducted electronically has grown remarkably with the extensive Internet usage because e-commerce recently has become standard platform for streamlining business flows and trading between organisations and consumers[1]. Nowadays, there is no doubt that the growth of information and communication technology is playing an important role in making individuals' life as easy as possible. E-commerce has become a unique method in providing internet users with information. Therefore, online trading can be considered a powerful way to across the world business in terms of increasing profit and cost-saving. Moreover, the evolution of the internet has influenced the way in which modern firms achieve their objectives, such as client satisfaction and the provision of high-quality products. 
International Journal of Web \& Semantic Technology (IJWesT) Vol.3, No.2, April 2012

The sales and Internet growth is the highest in Arabic community[1,2]. From this survey we strongly believed however, that e-commerce practices are not progressing at the same speed with the internet usage in the region. The world recently has faced extraordinary development in the communication field and online transactions in order to make clients' decisions much easier, and allowing greater flexibility. Taking into consideration the huge amount of information that is constantly available and being transferred between Internet users, which progressively raised some issues in usability of websites and in the human-computer interaction. It is pretty obvious that many companies focus on attracting online customers by using a number of methods. These methods include provision of services and goods purchased on the Internet and saving customers' time and preventing the barriers associated with distance. Many challenges especially related to computer-human interaction and interfaces with e-commerce websites issues however remain to be solved, which, if thoroughly investigated, would help in increasing the usability of such websites, and also reducing the numbers of customers that are driven-away from these sites.

There are three methods of data collection applied in this paper which they are questionnaire, interviews with the users and direct observation. The first and the second method have been used to obtain the demographic information of the users, and their feedback about the current websites and how they want the new websites to look like. Whereas the direct observation method used to test some usability specifications such as performance attributes. User's needs along with task and data have been analyzed in the analysis section. Additionally, design section suggested the new websites' design. The new systems have been tested and some screenshots have been provided in evaluation section to ensure that the new websites are functionally working well. Finally, this paper ends up with some recommendations regarding the newly designed websites presented to the management of JARIR bookstore and Ahmad Abdul wahed Company.

\section{AIMS AND OBJECTIVES}

This paper highlights the user-centred approach for website development, using a case study of both websites. In order to achieve user satisfaction, the user must be involved in every single stage of website development and his/her expectation and previous experience should be considered. Having a quick look at Jarir Bookstore and Ahmad Abdul wahed Trading Co's websites will simply determine their lack of usability and interactive design. This paper is therefore being conducted to:

- Investigate the usability and interactive design of the companies' websites.

- Analyse user needs and attempt to fulfil them using a user-centred methodology. All relative issues, such as physical limitations and the language spoken, will be properly addressed during development.

- Gather information about current and potential clients to be used to determine the weak aspects of the website as well as the features that clients want to see on the websites.

- Set usability goals and measure them against user preferences and willingness. These goals include attractiveness, satisfaction levels and overall impression of the website.

- Design and implement the new websites.

- Evaluate the websites, taking into account statements of usability criteria in order to move the usability forward.

\section{RELATED WORK}

Many studies have been delivered in the field of design to achieve efficient human-computer interaction. Saffer[5] defined interaction design as "the art of facilitating interaction between humans throughout products and services. Many studies have proved the benefits of improving 
International Journal of Web \& Semantic Technology (IJWesT) Vol.3, No.2, April 2012

website usability over the last decades. Recently, a huge amount of attention has been paid to the importance of user involvement in website development. E-commerce website usability, for instance, has an effect on the conversion rate of customers from traditional to online trading. Improving website usability not only reduces the cost of user support but also helps to keep clients and improve a firm's reputation [3]. Therefore, the main purpose of interaction design is to enhance communication between two or more human beings or a human and an artificial entity [5]. Carrying out user-centered development aims firms by assisting them achieve a high level of user satisfaction through making the system as easy to use as possible. It is widely agreed that customers naturally seek the easiest way to achieve their objectives. It can be said that complexity appears to be the biggest obstacle obstructing the success of electronic commerce, taking into account that some customers avoid using a given website when it is found to be difficult to navigate or to obtain information from. A usability evaluation is valuable in today's world of web-based activities and e-commerce.

\subsection{Advantages Of Using User-Centred Approach}

Bevan [4] stated that designer should take into account the user requirements and the expectations while developing website in order to satisfy the organization management. When developing an e-commerce website, taking a user-centered approach helps avoid many design and implementation errors. Bevan study showed that many websites are still unusable or difficult to navigate due to the following reasons:

- Organisations usually design websites that meet staff requirements rather than final user requirements.

- Website contents are frequently suitable as printed material but not when navigated online.

- Publishing material online is easy, and as a result it tends not to reach the same level of quality as other, more traditional publications.

- Many websites design projects do not employ design skills such as CSS and vision check techniques.

\subsection{Interaction Design}

The world of website design has completely understood what scholar John Heskett meant by his famous saying about interface design: "Design is to design a design to produce a design". Users used to consider the design to be how things look, but nowadays it has come to mean more than that [5]. This has forced web application designers to focus on the following issues:

- Focusing on users: Users do not usually care about the way the organization is run or managed. The only thing that matters is conducting tasks or achieving goals obviously advocated by designers.

- Finding alternatives: It is important to designers to find new solutions and options rather than choosing from predetermined ones. Google's experience in developing text advertisements is a good instance of this type of obstacles.

- Using ideation and prototyping: Many designers attempt to find a solution to serious issues by thinking carefully and then building a newly distributed model. However, design prototypes do not only bring the desired solution in the first attempt, as it is not necessary to solve the problem radically. The reason for this is that prototypes are not fixed and can be modified in any way. 
International Journal of Web \& Semantic Technology (IJWesT) Vol.3, No.2, April 2012

\subsection{Usability Goals}

In order to design an interactive website that meets all user requirements; it is necessary to first clarify the project goals. Usability goals are a set of attributes by which a given website can be tested and evaluated and the weak points determined and properly addressed. Calongne[6] stated that it is impossible to measure the usability of a website unless a number of usability goals are already set and measured. It is imperative to educate web application designers how to build highlevel websites, considering the importance of user involvement in every step. Due to the fact that setting usability goals is the backbone of web application design and implementation, a website developer first needs to identify the relevant usability goals, and then to quantify them using numerical values [6]. There is no doubt that planned and measurable design will save time and decrease costs by improving design decisions [7]. Additionally, it assists designers to shorten the design cycle and enhance the usability outcomes. Designing without clear objectives is described as "making blind choices". The main problem in the field of interface design is that software developers usually argue from their point of view on one hand, and deal with users as professional Internet users on the other. However, when a web application design project begins with clear specifications of usability goals and attributes, this makes design decisions much easier and more executable.

\subsection{Web Applications Characteristics}

A study conducted by Bruno et al. [8]presented a number of key aspects of web applications. These aspects suggest that there are a number of central characteristics, namely: user, task, technology and context.

- User: The user is simply anybody (a stakeholder) affected by the application interface, whether as a primary or secondary user. Many factors determine the way the user interacts with the computer, including computer skills, experience with web applications and attitudes to information technology in general. Loyalty is another significant factor, especially with e-commerce websites. When a user cannot find a certain item, he or she prefers to revisit the same website in the near future rather than turning to competitors.

- Task: This characteristic mainly focuses on the interaction style and interface design of a website. The distribution of contents on a web page is really important in assisting users to complete a task. In addition, it can be said that the usability of a website is always related to the type of task being conducted.

- Technology: The technological factor nowadays has a huge impact on website usability and accessibility. Given the diversity of the web applications and technologies implemented, web applications should incorporate high-quality implementation techniques in order to retain their users.

- Context: This characteristic represents the variables that must be taken into account based on the type of application. E-commerce websites, for example, need high-level security and more focus on the financial transactions conducted through the website. Ignoring these important aspects will definitely lead to the loss of countless current and potential clients. 


\section{WEBSITE DEVELOPMENT METHODOLOGIES}

\subsection{Balanced Website Design}

The balanced website design methodology is one of the most effective website development approaches, which highlights three objectives: usability, purpose and aesthetics of the design. These three pillars can each be predetermined and evaluated by a perfect requirement analysis conducted to gather the required information [9].

The major aim of using this methodology is to activate the art of interactive and effective website design, taking into account the merger of additional features with those applied in traditional methodologies such as Waterfall. In other words, the BWD approach is a carefully chosen combination of traditional and innovative website development methodologies which depends on a structured step-by-step process. The methodology consists of a 12-step cycle, forming four main phases of a website development project. The four phases are requirements (initial acquisition), design needs (building the picture), designing the solution and creating the website [9]. One of the advantages of the BWD approach is that it uses a clock metaphor to help provide the developing team with a general visualisation of the whole process and keep track of which step they are on during a project. Figure 1 clearly represents the twelve steps and their sequence.

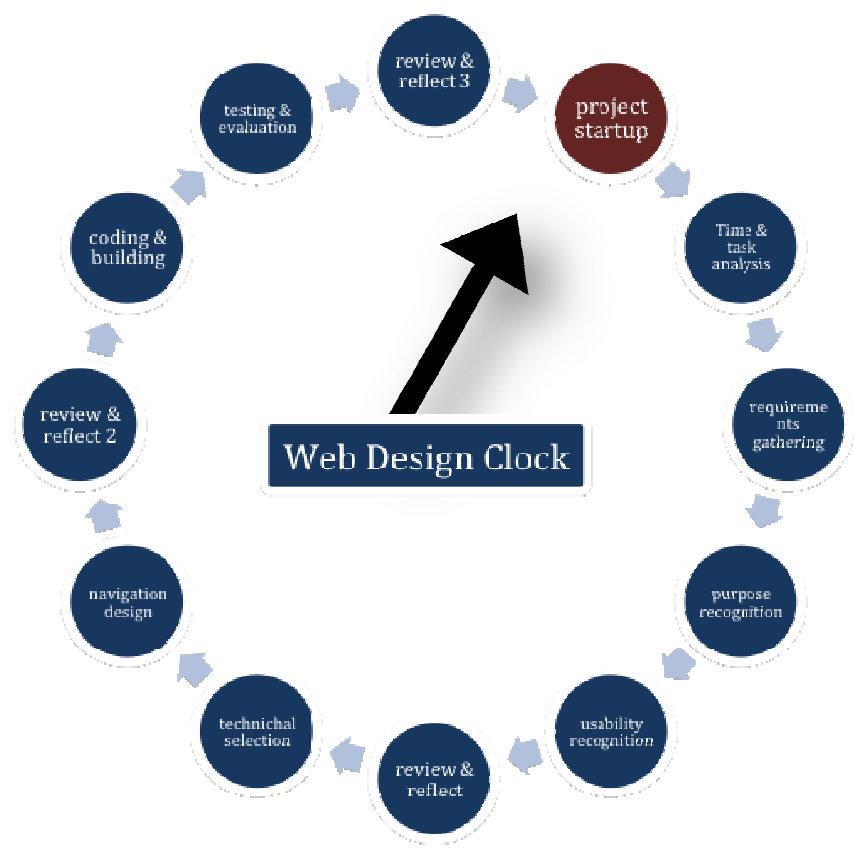

Figure1. BWD Clock Metaphor [9]

\subsection{User-Centred Web Development}

User-centred web development refers to "a design process for designing a web site that meets the needs of the users" [10]. This highlights the importance of user involvement in the design process in order to achieve the highest level of user satisfaction. User-centred web development is a greatly useful approach in assuring the usability of a website. Ease of use and navigability seem to be the top UCD benefits [10]. This approach comprises the following steps as in Figure 2: 


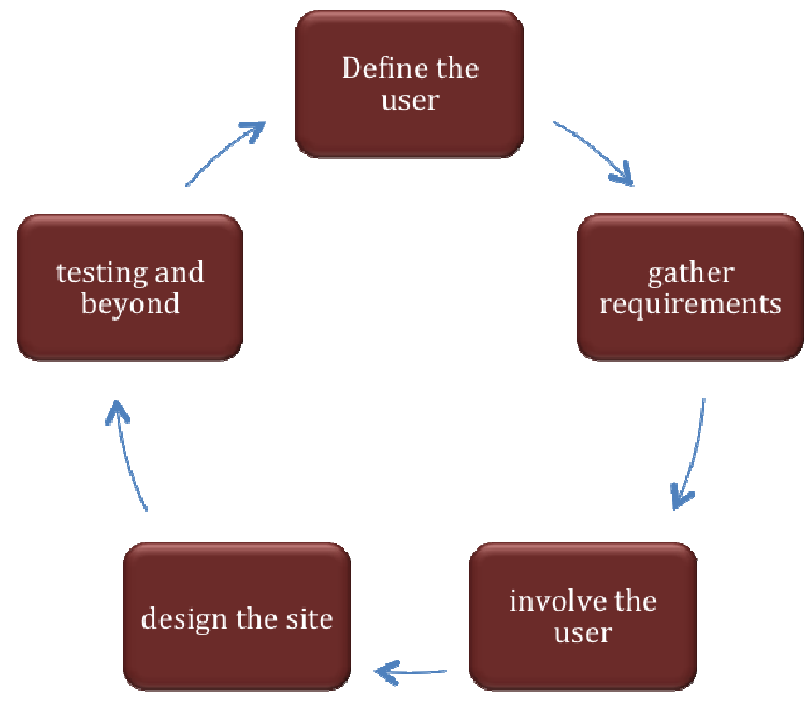

Figure 2. User-centered Devolopment Proccess [10]

\section{1) Define the user:}

It can be said that measuring ease of use differs from one user to another. As the internet has a virtual population of users, many scholars argue that it is impossible to design a website fulfilling all user requirements. This statement appears to be incorrect, as many current websites are well designed and meet visitor expectations, such as the CNN and BBC websites. The key point is defining the users, whether they are university students, children, senior citizens or any other type of users.

\section{2) Gather requirements:}

Gathering requirements assists developers to precisely determine the targeted user population, and use this knowledge to design a user-based website. User familiarity with computers, types of web page contents and connection speeds are the main issues discussed at this stage.

\section{3) Involve the user:}

Although the phrase "build it and they will come" is widely used by some website designers, it does not always work, as the contents must be specified based on user interests. Involving the user in the development process results in increased loyalty and trustworthiness.

\section{4) Design the site:}

This step involves the conceptual design of the website, including solving certain related issues such as navigation and page layout. This is followed by the physical design, which includes Java scripting, database design, HTML and interface design.

\section{5) Testing and beyond}

Usability testing takes place in this step to assure ease of use and navigability. Having tested the application, this is the appropriate time to release it and to promote it among the public. In the future, the website should be updated on a weekly or monthly basis. 
International Journal of Web \& Semantic Technology (IJWesT) Vol.3, No.2, April 2012

The methodology applied in this paper is user-centered approach provided by Daniel et al[11]. This approach consists of four main stages as follows: Analysis, setting usability specifications, design and prototype evaluation.

\section{DATA COLLECTION AND ANALYSIS}

\subsection{Data Collection}

Questionnaires are one of the most widely used methods adopted for gathering information. They are an easy way to rapidly gain users' demographic information and experience [12]. This data collection method has been chosen for this paper in order to investigate the usability attributes, which are explained in the following step. It is recommended by Pereeceet al.[12] that questions should be short, leading and easy to answer, so participants are encouraged to respond to all questions and provide true values. Brincket al. [13] stated that questionnaires could help researchers to obtain the required demographic information about visitors to the website under study. Additionally, they are the perfect tool to include different kinds of participants from various age groups and genders, taking into account the variety in educational qualifications, careers and information technology skills. The main questions in the questionnaire used for this study were derived from the Questionnaire for User Interaction Satisfaction (QUIS), which was developed by Pereeceet al, [12]. This questionnaire is widely adopted among information systems developers in order to enrich the study outcomes. The questionnaire approved for this study was designed using survs.com (a very powerful tool used to distribute surveys online). Social media networks and e-mails were used to distribute the questionnaire to the users. The questionnaire was bilingual (Arabic and English) so that as many participants as possible could be reached and included in the study. This decision was taken after the authors received several e-mails and messages on Facebook from a number of users expressing their unfamiliarity with the English language. Beside questionnaire, direct observation and interview have been used in gathering needed information. In addition to questionnaire, direct observation of the participants has also been applied as a methodology for collection data. The technique widely assisted to intensively involve the users in developing process. Finally interviews with participants, which is commonly adopted data collection strategy, with many other participants also played a significant role in discovering the weak points in both companies current websites.

\subsection{User And Task Analysis}

This type of analysis highlights the user-related information needed to bridge the gap between the user and the website designer. This information includes age, gender and highest educational qualification, as well as user experience in various areas such as trying online shopping. Moreover, this stage comprises all the activities that the website visitor is expected to undertake while navigating the website.

\subsection{Data Analysis And Findings}

\subsubsection{Demographic information:}

Analyzing data via questionnaire came out with many useful and meaningful results which can be used in developing the two websites. Using Survs.com as well as PASW software were significantly helpful to attain the results in due course. The survey involved 250 participants (162 females and 88 males). Their ages vary but most of them are between 18 to 25 years old, as shown in the Figure3. 


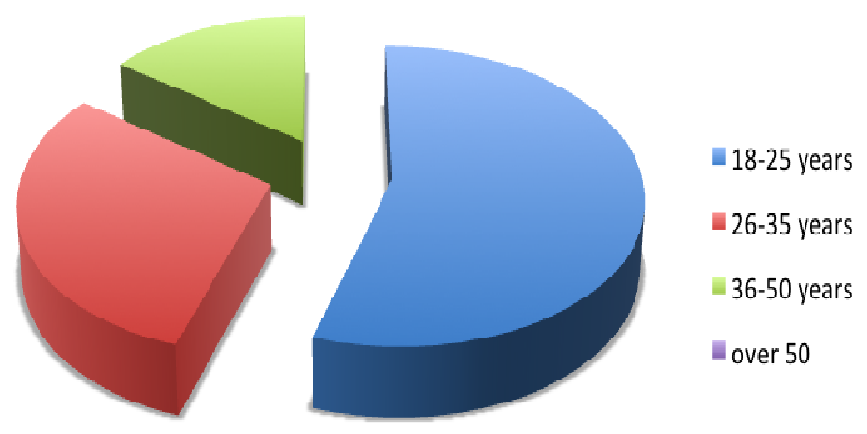

Figure 3. Age Groups of the Participants

According to the questionnaire results, most participants are higher education students. 140 of participants are Bachelor's forming the highest percentage at around $60 \%$. High school students are 22 whereas Master's are about $23 \%$ of the participants. There were a few $\mathrm{PhD}$ candidates forming just over 3\% of the participants as shown in Figure 4. Others did not express their educational qualifications. It is clearly noticed that the majority of the participants are highly educated so they will be helpful in providing constructive criticism and comments.

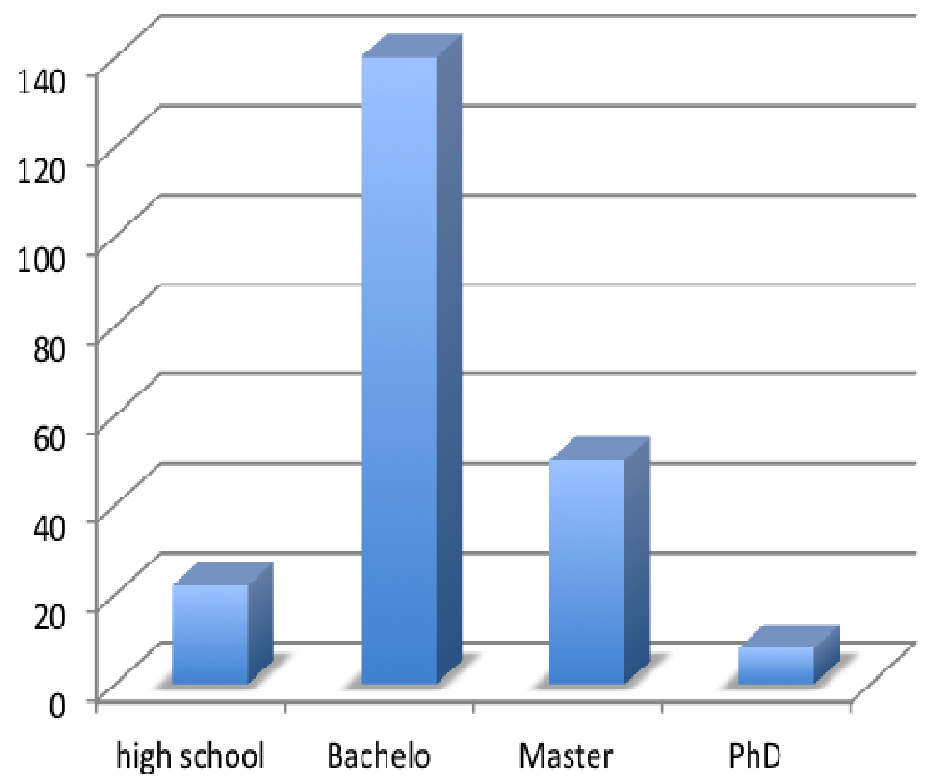

Figure 4. Percentages of academic qualifications among participants

\subsubsection{User Experience}

The study clearly shows that $90 \%$ of the participants have been interacting with technology of the Internet for a long period of time. As a result, this encourages us to benefit from their experience with e-commerce websites that they have visited and learn from other mistakes. Having asked the 
participants about the most common Internet browsers they preferred. As we can depict from the Figure 5 that Google Chrome seems to be the most favourable Internet browsers to many participants. Thus, the developed proposal will be tested on it.

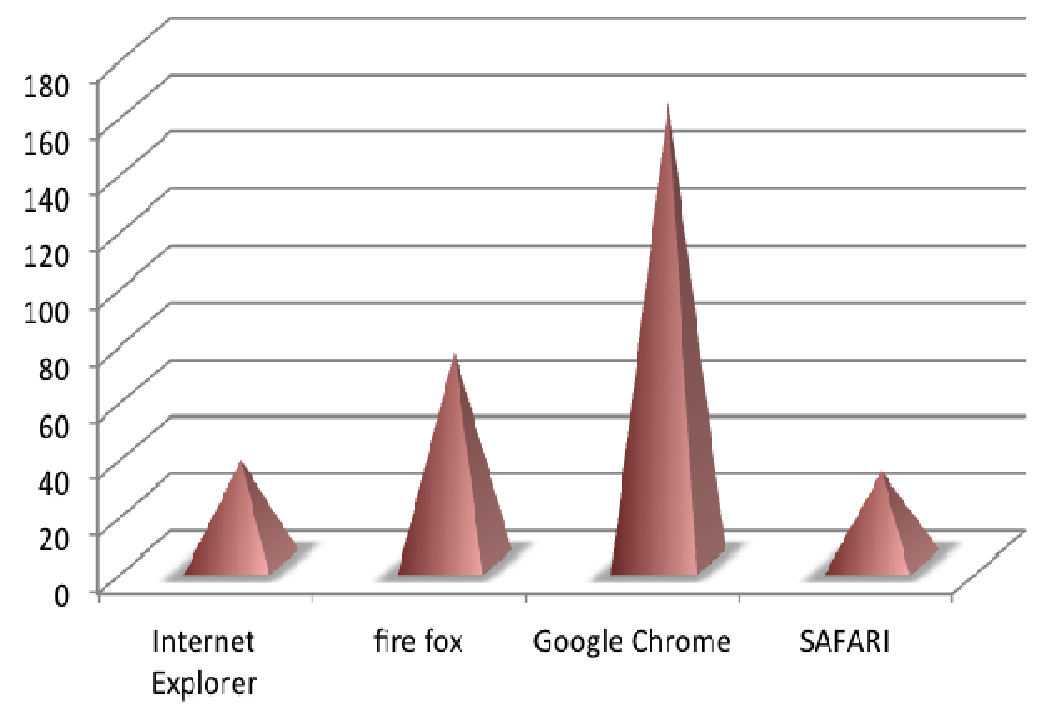

Figure 5 . Web browsers used by participants

\subsubsection{The Current Websites}

The data analysis has unfortunately shown that only 9 participants used the current websites more than 6 times. This clearly indicates that the websites are badly designed and distractive to many users. A number of participants stated that their visit was just to complete the survey. The Table 1 below is the usability specification table and could be descried as the most important part of this survey. It simply outlines the main issues in the current companies websites considering how the client thinks about it. In terms of websites navigation, 122 participants stated that there is need to click on Backward and forward buttons many times to complete a task. This indicates that the websites navigation needs to be investigated in order to make browsing the websites an easy experience. Some participants complain about the modernity and attractiveness of the interface design. Around $60 \%$ of the people involved in the study stated that the interface is not well designed and the contents of the page should be more organized than they are presently. This as a result affected using the website contents because 145 of the participants declared that they cannot use the websites contents simply and easily. The distribution and organization of the page contents seems to be the main factor behind this issue. Regarding the damaged pages and page errors, it seems to be the least problems faced while browsing the current website. Number of participants who think that the website is accessible is very similar to number of those who think it is not according to the table below. Learning the websites use appears as another problem discovered in this study. 127 participants believe that learning how to use the websites takes a long period of time due to the design-related issues discussed earlier. 
Table1. Usability Evaluation Attributes

\begin{tabular}{|c|c|c|c|c|c|c|}
\hline & $\begin{array}{l}\text { Strongly } \\
\text { agree }\end{array}$ & Agree & Neutral & Disagree & $\begin{array}{l}\text { Strongly } \\
\text { disagree }\end{array}$ & $\begin{array}{l}\text { It's } \\
\text { not } \\
\text { Availa } \\
\text { ble }\end{array}$ \\
\hline $\begin{array}{l}\text { I click on forward \& backward buttons } \\
\text { many times to complete a task }\end{array}$ & 70 & 52 & 44 & 45 & 30 & 9 \\
\hline $\begin{array}{l}\text { The website's interface is well } \\
\text { designed and modernly organised }\end{array}$ & 11 & 15 & 58 & 69 & 84 & 13 \\
\hline $\begin{array}{l}\text { I can use the website's contents easily } \\
\text { and simply }\end{array}$ & 20 & 39 & 38 & 67 & 78 & 8 \\
\hline $\begin{array}{l}\text { I have not faced any failure or } \\
\text { damaged pages while navigating }\end{array}$ & 32 & 51 & 78 & 32 & 42 & 15 \\
\hline $\begin{array}{l}\text { The site's contents are clearly } \\
\text { presented and organised }\end{array}$ & 9 & 55 & 39 & 72 & 63 & 12 \\
\hline $\begin{array}{l}\text { I can learn using the website in a short } \\
\text { period of time }\end{array}$ & 15 & 51 & 45 & 60 & 67 & 12 \\
\hline I can find information on the site easily & 20 & 58 & 25 & 63 & 69 & 15 \\
\hline All the site's contents are accessible & 42 & 52 & 53 & 51 & 43 & 9 \\
\hline $\begin{array}{l}\text { I can get assistance and support } \\
\text { quickly and reliably }\end{array}$ & 14 & 55 & 38 & 62 & 68 & 13 \\
\hline The overall impression of the site & 24 & 45 & 49 & 62 & 58 & 12 \\
\hline
\end{tabular}

\subsubsection{Future Websites}

Asking the users about their familiarity with online shopping websites, only 16 participants have not previously tried online transaction payment on online shopping websites. Around two third of the participants stated that they trust online shopping website on the Internet. This strongly encourages us to provide such a service to our clients taking into account that this addition will increase the customer loyalty and satisfaction. The service that the current website lacks are various. However, building an interactive shopping website seems to be the hope that our clients see in the development horizon. The survey shows that online shopping seems to be the most important feature to be in the newly designed website. This followed by providing delivery and coverage map where around $30 \%$ of the participants opted to be offered. Product evaluation 
International Journal of Web \& Semantic Technology (IJWesT) Vol.3, No.2, April 2012

service is another attractive feature suggested by a great deal of the clients. Many participants rose some issues related to the website security. In future work we can look to enhance the security related issues in these websites, especially the privacy and data confidentiality. Users' data and privacy should not to be disclosed to another entities without their consent [14].

\subsection{Critical Current Website Review}

In this section the current Ahmad Abdul wahed Trading Co and Jarir websites will be investigated. The data that was obtained by direct observation of the users and by the questionnaire will be examined and considered. All the issues related to the user-centred approach, such as key human factors, have been incorporated in the newly proposed website design. The following points are some issues that were raised after testing the existing company website under study:

\section{- Ease of navigation:}

Smith and Merchant [15] stated that ease of navigation is the factor that Internet users primarily focus on or are concerned about while surfing websites. It is widely agreed that random or badly designed interfaces complicate the process of navigation and make visiting websites a negative experience. Features such as drop-down menus could help to make the browsing experience as easy as possible, and assist the user in finding information easily.

\section{- Design attractiveness:}

Many people believe in the saying: "the first impression is the last impression". As users have various preferences and expectations, determining the most suitable colour or background image seems to be a critical issue to many website designers. In the case of the both websites under development, the present website colour and layout seem to annoy many of the questionnaire respondents. This consequently gives a bad impression of the website, driving away many prospective clients.

\section{- Ease of use:}

People experience difficulties while browsing the existing website. It is not easy to determine the right place for any bottom or link.

\section{- Functional correctness:}

Some of the disturbing and annoying factors for web users are errors and 'not found' pages that are often faced every day. The website designer should do his/her best to keep page errors at their lowest level, because such things may result in losing client loyalty, and it is believed that functionally correct websites definitely increase the image of creditability of the business to customers. Once users lose trust in a given website, they are much less likely to conduct any transactions or make online payments.

\section{- Clear and interactive interface:}

The current website interface is not that interactive due to lack of correct icon distribution, as well as the use of modern design tools. Employing design tools such as Photoshop and Javascript is an effective solution that should increase the site. 
International Journal of Web \& Semantic Technology (IJWesT) Vol.3, No.2, April 2012

\section{- Learnability:}

This usability-testing attribute is set in order to achieve certain goals. Firstly, establishing the average time spent getting to know and appropriately using the website. Secondly, determining a suitable time that users should spend learning how to use the website. Finally, discovering, in the future, whether users prefer to learn the website by seeking help or by trying it discover for themselves.

\section{- Efficiency:}

The information on the current website is very weak in terms of quality and quantity. Bhattiet al. [16] indicated that providing appropriate information is the main reason behind building websites nowadays. Clients tend to think that if a website is not trusted and legal, they don't want to risk placing their critical information and bankcard details on it. The existing website does not even have a privacy policy.

\section{- Accessibility:}

It is very important for a newly designed website to consider the expectations of all its clients. The colour of the background and foreground of the page plays an important role in term of accessibility, especially to people who are colour-blind. Differentiation between colours seems to be a critical issue for many Internet users, and as result of a lack of this many may not be able to clearly see the page contents.

\section{- Easy to remember:}

Brincket al. [13]indicated that websites should be designed to be easily memorised. They added that pages should all look like each other, and users should not need to remember how to navigate the website at every single visit. The existing website design does not follow this strategy, and as a result there is no logical sequence from one page to other. Additionally, icon distribution on the home page does not appear to do the website any favours.

\section{- Customer satisfaction:}

This attribute reflects the level to which the website users are comfortable with it and their opinion of the system as a whole. However, customer satisfaction is not only about the quality of the website design; it also includes after-sales services and business reputation.

\section{- Help and assistance:}

It is agreed that e-commerce projects must provide high-level support and real-time assistance in order to maintain clients' loyalty. Features such as live chat and real-time support are now the main advantages of successful e-commerce websites. Search bars should be placed in the correct location so website visitors can easily search for products.

\section{- Overall impression:}

Smith and Merchant [14] stated that having an attractive website is the best way to keep clients tuned to a business. All the attributes described above should be appropriately addressed in order to give clients a good impression. 


\section{NEW PROPOSED DESIGN}

Having determined the main weak points of the existing website, and taking into account the usability attributes described in the previous section, this section will lay out the shape of the website interface and the nature of the interaction between the system and the users.

\subsection{Header}

Each company logo was refined using Photoshop, and placed in the perfect location in the header, against the background of a professional photograph, in order to demonstrate the nature of the company's work. Considering the usability attributes that were discussed in last section, the website font should be adjustable for many reasons. Firstly, some visitors may have weak vision or visibility problems. Secondly, the web page contents and colours need to be suitable for different font sizes cases based on the type of contents. Although the current websites has the feature of multilingualism, the website is functionally bad because the Arabic language does not work. In the future, website visitors will be able to easily determine where to choose the suitable language from, at the top right side of the header. The feature of search bar is used to seek any product or service on the website. The bottom right of the header is the first place the user looks when opening the website. It is stated that Internet users look for a search box during their first visit to any website [17]. Users can also use advanced search, where they are able to stipulate a certain budget or brands. A well designed website provides an easy-to-use search tool in the correct location on the home page [18].

\subsection{Footer}

All the new offers, news and company-related releases can be delivered to the client through Stay Updated windows. It is a widely used feature, and helpful for keeping customers up-to-date with the business in terms of new updates and news. Businesses nowadays are starting to head towards social media websites. This is a unique way to promote the company products and services using Find Us button. Locate us using Google Maps helps clients to easily locate any branch on the map of state. Once they click the icon, a list of branches, address and contact details will appear across the Kingdom. Home is a button takes visitors to the home page from any page of the website whereas Feedback link navigates to a questionnaire where visitors will be able to provide comments about the services provided on the website as the website needs to be regularly updated. About us, Contact us are always key features in any usable website.

\subsection{Main body}

This part should include the following: Home button which is the most important button on the website as it simply overcomes the problem of being lost on any page of the site. Moreover, it leads to the most valuable page of any website: the home page [19]. Providing this feature reduces the number of clicks on forward and back buttons. Products is a direct links to all the types of products that both companies market. Aiming to increase the ease of navigation, the products should be organised alphabetically so customers can reach their destination quickly. Support page is where customers visit when they have a technical problem or broken item. It also allows them to request spare parts, or replacements if the product is still covered under a guarantee. The process should include the establishment of details regarding the model number, guarantee card number and date of purchase. Once the task is completed, the website should then provide the estimated date for the customer to return to the store and complete the other procedure. Site Map page simply comprises all the website links in one place. When users are lost 
or want to quickly find a particular page, they can easily find it on this page. The pages should be organised logically and based on their importance to the client [20].

\subsection{Side bar}

This includes $\mathrm{A}$ to $\mathrm{Z}$ index, registration, login and shopping cart icons. Additionally, clients can apply for discount card. In order to increase client loyalty, they can apply for a discount card, taking into account that the discounted amount depends on the total amount of the purchases. If customers want to browse the company's products offline, the easiest way is for them to download the product catalogue, which will be available on the side bar to browse at any time.

\section{SYSTEM EVALUATION}

- The websites we developed are not activated well enough so far to allow real online transactions. The reason behind this is that the researcher does not have a merchant account. Without an agreement with Visa or Master Corporation, which would be very costly to the project, users will not be able to have a real online shopping experience.

- Security seems to be a critical issue when designing an interactive e-commerce website. Internet users prefer websites that keep their information anonymous and their bank details safe. However, this paper is about enhancing the interface design of Ahmad Abdul wahed Trading and JarirCo's websites as well as addressing all the users' needs. There was not enough time to investigate website security, and it is better to leave this subject to a separate research paper.

- Colour blindness is one of the critical issues in terms of website development. The new website proposals has been checked on Vischeck.com to ensure that it can be clearly seen by colour-blind users.

\section{CONCLUSION}

Looking at most e-commerce websites nowadays clearly reveals that users' needs are not the backbone of website design. Many website designers ignore user expectations and preferences until the final functional implementation, and eventually release websites on the Internet without any regard for their users. Ease of navigation and use, user satisfaction and attractiveness are advantages that will never be gained unless a user-centred approach is adopted and users are involved at every step of the development process. A number of websites are developed based on Waterfall website development methodology, although a user-centred approach has more advantages to both users and website administrators, as discussed earlier in this report. The methods used to gather data in this paper were a questionnaire, direct observation and interviews with users. All the gathered data was analysed in detail and used to complete the usability specification table. Applying a user-centred approach to the existing websites has revealed many issues in terms of bad design and weak creation of the website. The design section proposed a new database design for the website, along with appropriate and logical tables. Once the company management adopts this proposal, it will bring many advantages to the business. The website evaluation section discussed a number of issues that were faced during the development of the website. 
International Journal of Web \& Semantic Technology (IJWesT) Vol.3, No.2, April 2012

\section{RECOMMENDATIONS}

- Human factor is very important in designing an interactive website nowadays. The following recommendation are provided taking into account the main standards of usercentered website design approach because adopting such a factors would be valuable in order to reach clients satisfaction. At the end of this study we are advising Ahmad Abdulahed Company and Jarir Bookstore managements to consider these recommendations and involve them in the futuristic website development as they are a result of academic study and experts' thoughts.

- Provision of shopping cart in the newly designed website needs inventory management systems along with a perfectly designed online payment system. It is argued that these services are costly. However, these features would assist to automate the business process as well as change the way that users shop to a faster and more enjoyable one. We expect that the advantages of providing online shopping system will overweight the development costs and as a result all the costs will be paid off in a short period of time.

- One of our recommendations is uploading the proposed website temporarily and let the clients to navigate it and provide their feedback about it. This highlights some issues that might have been missed from our minds while developing the current website. Additionally, we could clearly determine whether or not addressed all the key point of user-centered website development.

- Two of the websites that provide perfect search engine are Isohunt and Google. The search in these websites can be placed using user's voice. This feature is very useful in order to enhance the website accessibility as well as to help keyboard-less visitors navigate the website. We highly recommend that this feature should be on the development list in the near future.

- Live chat is one of the real time support methods. In the field of comments in the questionnaire distributed, many users mentioned their willing to see this feature in the new website. It has been added to the new design as a suggestion but not activated yet as it needs a lot of programming works. Once this feature is adopted in the new website, it will definitely raise the quality of the support and assistance offered to our clients.

- We recommend the firm management to subscribe in Merchant account. Many participants are willing to pay using their debit and credit cards. Therefore, there is necessity to provide this on the website as soon as possible. However, this proposal should be done taking into account the protection of clients' bank account details.

Some features recommended in this paper could be costly from the company management perspective. However, applying a quick cost and benefit study would simply explain how the website users could benefit from along with the satisfaction that the visitors will feel using the new website.

\section{ACKNOLEDMENT}

Our special thanks always go to our parents and siblings for their ongoing encouragement in achieving this paper. Words cannot express the amount of gratitude and appreciation we owe them. 
International Journal of Web \& Semantic Technology (IJWesT) Vol.3, No.2, April 2012

\section{REFERENCES}

[1] Brian J Corbitt, Theerasak Thanasankit, and Han Yi, "Trust and e-commerce: a study of consumer perceptions," Selected Papers from the Pacific Asia Conference on Information Systems, vol. 2, no. 3, pp. 203-215, 2003.

[2] "Economic research and studies departmen". Council of Saudi Chambers of Commerce and Industry, Riyadh, Saudi Arabia October 2000.

[3] Jacko, J. Human-Computer Interaction: New Trends. Germany: Springer-Verlag Berlin Heidelberg, 2009.

[4] Bevan, N. (1998) Usability Issues in Website Design. Teddington, UK: Serco Limited.

[5] Saffer, D. (2010) Designing for Interaction, Second Edition: Creating Innovative Applications and Devices. USA: New Riders.

[6] Calongne, C. (2001) Designing For Website Usability. The Jurnal of Computing in Small Coleague, (3), pp. 39-45.

[7] Mayheaw, D. (1999) The Usability Engineering Lifecycle: A Practitioner's Handbook For User Interface Design. USA: Academic Press.

[8] Bruno, V., Tam, A, and Thom, J. (2005) Characteristics of Web Applications That Affect Usability: A Review. Canberra, Australia: Proceedings of OZCHI.

[9] Lawrence, D. and Tavakol, S. (2007) Balanced Website Design: Optimizing Aesthetics, Usability and Purpose. London: Springer-Verlag Limited.

[10] Lazar, J. (2001) User-Centered Web Development. USA: Jones and Bartjett Publishers International.

[11] Daniel D McCracken and Rosalee J Wolfe, User-Centred Web Site Development: A HumanComputer Interaction Approach. Prentice Hall, 2003.

[12] Preece, J., Rogers, Y. and Sharp, H. (2009) Interaction Design. 2nd ed. New York; Chichester: Wiley.

[13] Brinck, T., Gergle, D. and Wood, S.D. (2002) Usability for the Web: designing web sites that work. San Francisco: Morgan Kaufmann.

[14] H. Aldabbas, T. Alwada'n, H. Janicke and A. Al-Bayatti, "Data Confidentiality in Mobile Ad hoc Networks", International Journal of Wireless \& Mobile Networks (IJWMN), vol. 4, no. 1, February 2012.

[15] Smith, B.A and Merchant, E.J. (2001), "Designing an attractive web site: variables of importance", Proceedings of the 32nd Annual Conference of the Decision Sciences Institute, San Francisco, CA.

[16] Bhatti, N., Bouch, A. and Kuchinsky, A. (2000), "Integrating user-perceived quality into web server design", Computer Networks, Vol. 33 Nos. 1-6, pp. 1-16.

[17] Krug, Steve. (2009) Don't make me think!: A common sense approach to Web usability. 2nd ed. Berkeley, CA: New Riders.

[18] Nielsen, J. (2001) Search: Visible and Simple [WWW]. Available from: http://www.useit.com/alertbox/20010513.html [Accessed 10/12/2011].

[19] Nielsen, J. (2002) Top Ten Guidelines for Homepage Usability [WWW]. Available from: http://www.useit.com/alertbox/20020512.html [Accessed 15/12/2011]. 
[20] Nielsen, J. (2008) Site Map Usability [WWW]. Available from: http://www.useit.com/alertbox/sitemaps.html [Accessed 10/12/2011].

\section{Authors}

Ali Alghamdi Received his BSc in Computer Science from Taif University, TaifKSA in 2009 and his MSc in Information Systems Management in 2012 from De Montfort University, Leicester, UK. Ali is currently planning to continue for $\mathrm{PhD}$ study.

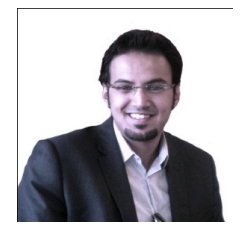

HamzaAldabbas : I am currently a PhD student at STRL (Software Technology Research Laboratory), De Montfort University, Leicester - United Kingdom. Obtained M.Sc degree in computer science from Al-Balqa'a Applied UniversityJordan. And B.Sc. degree in Computer Information System from the same university. I am also a part time lecturer at De Montfort University, involved in teaching and project supervision at B.Sc. \& M.Sc levels (2010-until now). My research interests are in mobile ad hoc networks, wireless sensor networks, vehicular ad hoc networks, security management mobile \& wireless networks, policy based management systems and recently interested in human-computer

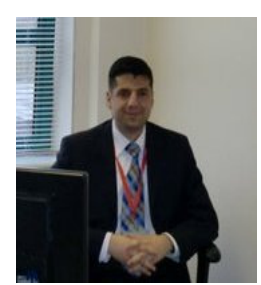
interaction design.

Mohammad Alshehri Received his BSc in Management Information Systems from King Abdulaziz University, Jeddah-KSA in 2008 and his MSc in Information Systems Management last year from De Montfort University, Leicester, UK. He is currently planning for resuming his postgraduate study in the field of Humancomputer Interaction.

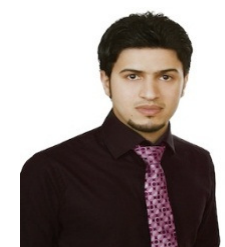

